\title{
WIRELESS SENSOR NETWORKS IN AGRICULTURE: A REVISION
}

\author{
Matheus Nascimento Czelusniak, Rodrigo Modesto Rodrigues, Luma Alves Lopes \\ and Maria Salete Marcon Gomes Vaz \\ Universidade Estadual de Ponta Grossa, Brazil
}

\begin{abstract}
Food safety is vital for the development of a country and its population. Guaranteeing an acceptable quality standard for food production, one that causes no damage to the consumer's health, is a priority for agricultural producers, especially for those in the exportation market. Failure in keeping those standards results in severe restrictions by other countries - an example being the prohibition of meat export stored in refrigerators investigated in the Brazilian police operation Carne Fraca - which result in deep impacts in the economy of a country. The development and enhancement of food traceability systems is a field of study that brings benefits for producers. As such, we proposed a systematic review of literature about the use of wireless sensor networks (WSN) in agriculture. The applications of WSN found in the process of the systematic review are traceability systems in the chain of production, monitoring systems and the enhancement of WSN
\end{abstract}

\section{KEYWORDS}

Wireless Sensor Network, Agriculture, Systematic Review

\section{INTRODUCTION}

In agriculture, the use of WSN - networks comprised of many distributed nodes, autonomous and with high degree of cooperation between its sensors (LOUREIRO, et al. 2003) - for the analysis of characteristics such as soil humidity and soil temperature, help farmers avoid wastes and failures in the growth of plantations. For these analyses to be efficient, the need for effective data collection through WSN turns into a necessity. The utilization of wireless sensor network is fundamental in agriculture, has growth potential and is useful for more assertive and rapid decision making.

With the objective of improving data collection in a WSN, a systematic review of literature was made, searching for the understanding of how this technology is being used in agriculture and in traceability systems.

\section{WIRELESS SENSOR NETWORKS}

According to LOUREIRO et al., (2003), wireless sensor network (WSN) are different from traditional computer networks in aspects such as a greater number of nodes, restrictions in energy supply and the existence of auto-configuration mechanisms due to problems such as communication failure and the loss of sensor nodes.

A WSN tends to be autonomous and requires a high degree of cooperation to execute the tasks defined by the network. The challenges and project considerations of WSN are quite different from the ones in traditional networks.

In WSN, each node is equipped with a variety of sensors such as infrared, temperature, pressure and heat. These nodes can be organized in clusters where at least one of the sensors must be able to detect an event in the region, process it and make the decision of doing (or not) a broadcast of the results to other nodes. It is expected that wireless sensor networks become available everywhere, executing many different tasks. 


\section{MATERIALS AND METHOD}

The usage of wireless sensor networks is fundamental in agriculture, has growth potential and is useful for a more assertive and fast decision making. This systematic review has as its objective the answer to the following questions: how do WSN are used in agriculture and what are the major methods used in food traceability systems. We arrived at those questions through analysis of which technologies are suitable for farming in the industry 4.0: the agriculture 4.0 (BRAUN et al., 2018). Once the questions were defined, the definition of criteria for the selection of relevant articles was initiated.

While agriculture 4.0 is an important theme for the food safety of innumerous countries, the literature about the subject is not well-developed in all of them. In Brazil, for example, techniques related to this field of study are not distributed enough to achieve a general answer to the questions this review makes.

Once the criteria for the article selection was defined, a search for relevant studies was initiated. Three bases of research were utilized - ACM Digital Library, IEEE Xplore Digital Library and ScienceDirect - and the terms of research used were "Wireless Sensor Network", "Agriculture", "Traceability" and "Smart Farm". To better organize the selection criteria and the systematic review as a whole, a software called StArt (State of the Art through Systematic Review), developed by the Research Laboratory in Software Engineering of the Computer Department of the Federal University of Sao Carlos (UFScar), was utilized.

\section{SYSTEMATIC REVIEW}

In total, 188 articles were found, distributed between the three bases of research, as seem in Table 1, Through study of the accepted articles in the selection phase of the systematic review, a profile about the uses of WSN in agriculture took shape. Three fields of study rose to prominence: traceability systems in the chain of production, monitoring systems and the enhancement of WSN.

Table 1. Number of Articles Evaluated

\begin{tabular}{llll}
\hline Bases of Research & Number of articles & Accepted articles & Rejected articles \\
\hline ACM Digital Library & 48 & 21 & 27 \\
\hline IEEE Xplore Digital Library & 83 & 31 & 52 \\
ScienceDirect & 57 & 33 & 24 \\
Total & 188 & 85 & 103 \\
\hline
\end{tabular}

The articles about traceability systems propose the use of RFID tags based on the EPCglobal standard and the implementation of a platform where producers share data about their farms. This data would, in turn, be used to define a quality standard that could be evaluated by other farmers. As an example, we have the SPIDER platform (Supply-chain Pedigree Interactive Dynamic Explore), described in WANG, et al. (2012). Wang proposes a comparison between the data received and the international standard for evaluation of food security (HACCPs), allowing the final consumer the chance to evaluate the results of each product.

The monitoring systems, on the other hand, focus on data collection - such as soil humidity and soil temperature - and delegate the analysis of these data to the user, who them decides the best course of action. Examples of systems like this one are described in FUKATSU, et al. (2014) e SANTOS, et al. (2018). Santos, in particular, proposes that the collected data should be provided to a prevision engine who, in turn, can anticipate problems in the field.

The articles about the enhancement of WSN have a broader scope of study. PANDE et al. (2012) and ZENI et al. (2015) focus on better methods of distribution in sensors for data collection and the reduction in production and energy costs of sensors. ALI et al. (2017), describes the development of security protocols.

\section{FINAL CONSIDERATIONS}

This article had as its objective the understanding of how wireless sensor network are being applied in agriculture and the various methods by which traceability systems are developed. From the 188 articles 
evaluated, 103 were rejected, the main reason being that, while they talked about wireless sensor networks, they weren't specifically about its uses in agriculture. Observing the global scenery, it is possible to perceive a growing worry with the processes of the food supply-chain. Analyzing the results of this systematic review of literature, it is evident that, in many parts of the world, there is the same worry regarding the monitoring of the production process. This worry is justified if these countries would like a more analytical administrative choice and information that could be used to make the quality of the food that reaches the consumer more reliable. In conclusion, it is possible to perceive through this study that the general areas of research in the use of WSN in agriculture are monitoring systems and the enhancement of WSN.

\section{REFERENCES}

Ali, R; Pal, A. K.; Kumari, S.; Karuppiah, M.; Conti, M. A secure user authentication and key-agreement scheme using wireless sensor networks for agriculture monitoring, 2017.

Braun, A.; Colangelo E.; Steckel T. Farming in the era of Industry 4.0, 2018

Czelusniak, M. N.; Rodrigues, R. M.; Lopes, L. A.; Vaz, M. S. M. G. Filtragem de dados baseada em Filtro de Kalman para a persistência de dados na rastreabilidade de grãos. Anais do CONAITEC 2018 - Sistemas Sustentáveis no Agronegócio.

Fukatsu, T.; Hirafuji, M. Web-based sensor network system "Field Servers" for practical agricultural applications, 2014.

Loureiro, A. A. F.; Nogueira, J. M. S.; Ruiz, L. B.; Mini, R. A. D. F.; Nakamura, E. F.; Figueiredo, C. M. S. Redes de Sensores Sem Fio, 2003.

Oliveira, Waldri Dos Santos; Gonçalves, Eduardo. Nunes. Implementação em c: filtro de Kalman, fusão de sensores para determinação de ângulos. ForScience: revista científica do IFMG, Formiga, v. 5, n. 3, e00287, jul./dez. 2017.

Pande, M.; Choudhari, N. K.; Pathak, S. Energy Efficient Hybrid Architecture and Positioning of Sensors in WSN for Precision Agriculture, 2012.

Prado, Maeli. Governo suspende temporariamente exportações de carne de aves da BRF à Europa. 2018. Disponível em: .Acess in: mar. 2019.

Santos, U. J. L. D.; Pessin, G.; Costa, C. A. D.; Righi, R. d. R. AgriPrediction: A proactive internet of things model to anticipate problems and improve production in agricultural crops, 2018.

Wang, L.; Ting, J.S.L.; Ip, W.H. Design of Supply-chain Pedigree Interactive Dynamic Explore (SPIDER) for food safety and implementation of Hazard Analysis and Critical Control Points (HACCPs). 2012.

Zeni, M.; Mbitiru, E. O. R.; Nyambura, A.; Samuel, L.; Fleming, K.; Weldemariam, K. Low-power Low-cost Wireless Sensors for Real-time Plant Stress Detection, 2015. 